Pacific Journal of Mathematic 


\title{
ON MATRIX MAPS OF ENTIRE SEQUENCES
}

\author{
H. B. SKERRY
}

In this note the linear space $E$ of entire sequences and various subspaces are considered. The fact that $E$ represents the space of entire functions is emphasized by determining subspaces in terms of order and type. Matrix maps between the subspaces are characterized, and a related result and an example are also given.

1. Subspaces of $E$ determined by order. First we recall that if $M(r)=\max |f(z)|$ on the circle $|z|=r$, then the order of the entire function $f$ is $\rho=\lim \sup [(\log \log M(r)) / \log r]$, and its type is $\tau=\lim \sup \left[(\log M(r)) / r^{\rho}\right]$, assuming $\rho<\infty$. If $f(z)=\sum_{0}^{\infty} x_{n} z^{n}$ is an entire function, then it has finite order $\rho$ if and only if $\mu=$ $\lim \sup _{n}\left[n \log n / \log \left(1 /\left|x_{n}\right|\right)\right]$ is finite, and then $\rho=\mu([1]$, p. 9$)$.

Definition 1.1. We say the complex sequence $x=\left\{x_{n}\right\}_{0}^{\infty}$ is analytic if the corresponding power series $\sum x_{n} z^{n}$ has radius of convergence $r(x)>0 . \quad x$ is an entire sequence if $r(x)=\infty$, and its order and type are those of the power series.

Definition 1.2. For each $\rho \in[0, \infty)$, let $O(\rho)$ be the set of entire sequences of order not exceeding $\rho$. For each $\rho \in(0, \infty]$, let $O^{\prime}(\rho)$ be the set of entire sequences of order less than $\rho$.

Definition 1.3. If $0 \leqq \rho<\infty$, let $\rho^{+}$be the class of real sequences $\left\{\rho_{n}\right\}_{1}^{\infty}$ such that $\rho_{n} \searrow \rho$ and $\rho_{n}>\rho$. If $0<\rho \leqq \infty$, let $\rho^{-}$be similarly defined, but with $\rho_{n} / \rho$ and $0<\rho_{n}<\rho$.

DEFINITION 1.4. Let $\alpha=\left\{\alpha_{n}\right\}_{0}^{\infty}$ be a complex sequence with no zero-terms, and let $s(\alpha)=\left\{\right.$ complex $\left.x \mid \alpha_{n} x_{n} \rightarrow 0\right\}$.

If we define $\|x\|_{\alpha}=\sup \left|\alpha_{n} x_{n}\right|$, then $\left(s(\alpha),\|\cdot\|_{\alpha}\right)$ is a $B K$ space ([8], Satz 5.4).

We will now characterize those matrices $A=\left(a_{n k}\right)$ which map $s(\alpha) \rightarrow s(\beta)$. If $f$ is a continuous linear functional on $s(\alpha)$, then $f$ can be represented in the form $f(x)=\sum c_{n} \alpha_{n} x_{n}$, where $\sum\left|c_{n}\right|<\infty$ ([8], Satz 5.4). It is easily shown that the coefficients $c_{n}$ in this representation are unique, and that $\|f\|=\sum\left|c_{n}\right|$. Suppose $A$ maps $s(\alpha) \rightarrow$ $s(\beta)$. Define $f_{n}(x)=\beta_{n} \sum_{k} a_{n k} x_{k}$. It is known ([7], Corollary 5, p. 204, or [8], Satz 4.4) that a matrix map between $F K$ spaces is continuous, and $f_{n}=\beta_{n} P_{n} \circ A$ (where $P_{n}$ is the $n$th projection map), so $f_{n}$ is a continuous linear functional on $s(\alpha)$ with norm $\left\|f_{n}\right\|=\sum_{k}\left|\beta_{n} a_{n k} / \alpha_{k}\right|$. 
$\beta_{n} y_{n} \rightarrow 0$ because $y=A x \in s(\beta)$. It follows that for each $x$ in $s(\alpha)$, $f_{n}(x) \rightarrow 0$ and $\sup _{n}\left|f_{n}(x)\right|<\infty$, so the uniform boundedness principle gives

$$
\sup _{n} \sum_{k}\left|\beta_{n} a_{n k}\right| \alpha_{k} \mid=M \neq \infty \text {. }
$$

Because $e^{k}$ (the sequence having 1 in the kth coordinate and 0's elsewhere) is in $s(\alpha)$, we also have

(1.6) $A e^{k}=\left\{a_{n k}\right\}_{n}=$ the $k$ th column of $A$ is in $s(\beta)$ for each $k$.

We show that the necessary conditions (1.5) and (1.6) are also sufficient for $A$ to map $s(\alpha)$ into $s(\beta)$. If $x \in s(\alpha)$, then $\alpha_{k} x_{k} \rightarrow 0$, so $\sum_{k}\left|a_{n k} x_{k}\right|=\mathcal{O}(1) \sum_{k}\left|a_{n k} / \alpha_{k}\right|<\infty$ by (1.5). Thus $A x$ is defined on $s(\alpha)$. Now let $\varepsilon>0$ be given and choose $N$ so that $k>N \Rightarrow\left|\alpha_{k} x_{k}\right|<$ $\varepsilon / M$. Then

$$
\left|y_{n}\right| \leqq \sum_{k=0}^{N}\left|a_{n k} x_{k}\right|+(\varepsilon / M) \sum_{k=N+1}^{\infty}\left|a_{n k}\right| \alpha_{k} \mid,
$$

and (1.6) and (1.5) give

$$
\lim \sup _{n}\left|\beta_{n} y_{n}\right| \leqq 0+(\varepsilon / M) M=\varepsilon .
$$

It follows that $y=A x \in s(\beta)$. We have proved

THEOREM 1.7. In order that $A$ map $s(\alpha) \rightarrow s(\beta)$ it is necessary and sufficient that

$$
\sup _{n} \sum_{k}\left|\beta_{n} a_{n k} / \alpha_{k}\right|=M \neq \infty
$$

and

$$
\text { each column of } A \text { is in } s(\beta)
$$

be satisfied.

THEOREM 1.8. Let $\left\{\alpha^{j}\right\}_{j=1}^{\infty}$ and $\left\{\beta^{i}\right\}_{i=1}^{\infty}$ be sequences of sequences $\alpha^{j}=\left\{\alpha_{n}^{j}\right\}_{n=0}^{\infty}$ and $\beta^{i}=\left\{\beta_{n}^{i}\right\}_{n=0}^{\infty}$ with the property that $k>j \Rightarrow s\left(\alpha^{k}\right) \subseteq$ $s\left(\alpha^{j}\right)$ and $s\left(\beta^{k}\right) \subseteq s\left(\beta^{j}\right)$. Let $S=\bigcap s\left(\alpha^{j}\right)$ and $T=\bigcap s\left(\beta^{i}\right)$. Finally, we ask that for every $j$ there exists $k>j$ such that $\sum\left|\alpha_{n}^{j}\right| \alpha_{n}^{k} \mid<\infty$, and that for every $i$ there exists $\measuredangle>i$ such that $\beta_{n}^{i} / \beta_{n}^{l} \rightarrow 0$. Then the matrix $A$ maps $S \rightarrow T$ if and only if

(1.9) for each $i$ there exist $j$ and $M$ such that $\left|\beta_{n}^{i} a_{n k} / \alpha_{k}^{j}\right| \leqq M$ for all $n, k$.

Proof. First, we remark that $s(\alpha) \subseteq s(\beta)$ if and only if $\lim \sup \left|\beta_{n} / \alpha_{n}\right|<\infty$. Clearly, the set $\left\{e^{k}, k=0,1, \cdots\right\}$ is a Schauder 
basis for $s(\alpha)$, so it follows ([9], Satz) that $A$ maps $S \rightarrow T$ if and only if for every $i$ there is a $j$ such that $A$ maps $s\left(\alpha^{j}\right) \rightarrow s\left(\beta^{i}\right)$, i.e., if and only if both of

(1.10) for each $i$ there is a $j$ such that $\sup _{n} \sum_{k}\left|\beta_{n}^{i} a_{n k} / \alpha_{k}^{j}\right|<\infty$,

$$
\left\{a_{n k}\right\}_{n} \in T \text { for each } k \text {, }
$$

hold. It is obvious that (1.10) implies (1.9). Conversely, let $i$ be given and let $j$ and $M$ correspond to $i$ as in (1.9). Choose $r>j$ so that $\sum_{k}\left|\alpha_{k}^{j} / \alpha_{k}^{r}\right|<\infty$. Then

$$
\sum_{k}\left|\beta_{n}^{r} a_{n k}\right| \alpha_{k}^{r}\left|=\sum_{k}\right| \beta_{n}^{i} a_{n k}\left|\alpha_{k}^{j}\right| \cdot\left|\alpha_{k}^{j}\right| \alpha_{k}^{r}\left|\leqq M \sum_{k}\right| \alpha_{k}^{j}\left|\alpha_{k}^{r}\right|<\infty,
$$

so (1.9) implies (1.10). To complete the proof we need only show that (1.9) implies (1.11). Let $i$ be given and choose $\ell>i$ so that $\beta_{n}^{i} / \beta_{n}^{l} \rightarrow 0$. Let $j$ and $M$ correspond to $\ell$ as in (1.9). Then $\left|\beta_{n}^{l} a_{n k}\right| \leqq$ $M\left|\alpha_{k}^{j}\right|$ for every $n$, so $\left|\beta_{n}^{i} a_{n k}\right| \leqq\left|\beta_{n}^{i}\right| \beta_{n}^{l}|M| \alpha_{k}^{j} \mid \rightarrow 0$ as $n \rightarrow \infty$, and $\left\{a_{n k}\right\}_{n} \in s\left(\beta^{i}\right)$.

Now let $\left\{\rho_{j}\right\} \in \rho^{+}$and let $\alpha_{n}^{j}=n^{n / \rho_{j}}$. It is readily verified that $O(\rho)=\bigcap s\left(\alpha^{j}\right)$.

THeOREM 1.12. The matrix A maps $O(\rho) \rightarrow O(\mu)$ if and only if

for each $t>\mu$ there exist $r>\rho$ and $M$ such that $n^{n / t}\left|a_{n k}\right|\left(1 / k^{k / r}\right) \leqq M$ for all $n, k$.

Proof. Let $\left\{\mu_{i}\right\} \in \mu^{+}$and set $\beta_{n}^{i}=n^{n / \mu_{i}}$, so that $O(\mu)=\bigcap s\left(\beta^{i}\right)$. The hypotheses of Theorem 1.8 are met, so $A$ maps $O(\rho) \rightarrow O(\mu)$ if and only if (1.9) holds. But this is equivalent to (1.13).

We now consider $O^{\prime}(\rho)$. If we choose $\left\{\rho_{j}\right\} \in \rho^{-}$, then $O^{\prime}(\rho)=$ $\mathbf{U} O\left(\rho_{j}\right)$.

THEOREM 1.14. The matrix $A$ maps $O^{\prime}(\rho) \rightarrow O^{\prime}(\mu)$ if and only if (1.15) for each $r \in(0, \rho)$ there exist $t \in(0, \mu)$ and $M$ such that $n^{n / t}\left|a_{n k}\right|\left(1 / k^{k / r}\right) \leqq M$ for all $n, k$.

Proof. We observe first that ([9], Satz, part (4)) remains true if the component spaces are merely $F K$ spaces, nested or not, as long as their unions are linear spaces. (We will have occasion in the sequel to utilize this observation.) It follows that $A$ maps $O^{\prime}(\rho) \rightarrow$ $O^{\prime}(\mu)$ if and only if

for each $j$ there is an $i$ such that $A$ maps $O\left(\rho_{j}\right) \rightarrow O\left(\mu_{i}\right)$. 
By Theorem 1.12, this happens if and only if

for each $j$ there is an $i$ such that for every $t>\mu_{i}$ there exist $r>\rho_{j}$ and $M$ such that $n^{n / t}\left|a_{n k}\right|\left(1 / k^{k / r}\right) \leqq M$ for all $n, k$.

But this is equivalent to (1.15).

Similar applications of ([9], Satz) give the next two theorems.

THEOREM 1.16. The matrix $A$ maps $O^{\prime}(\rho) \rightarrow O(\mu)$ if and only if (1.17) for each $t>\mu$ and $r \in(0, \rho)$ there is an $M$ such that $n^{n / t}\left|a_{n k}\right|$ $\left(1 / k^{k / r}\right) \leqq M$ for all $n, k$.

THEOREM 1.18. The matrix $A$ maps $O(\rho) \rightarrow O^{\prime}(\mu)$ if and only if (1.19) there exist $t \in(0, \mu), r>\rho$, and $M$ such that $n^{n / t}\left|a_{n k}\right|\left(1 / k^{k / r}\right) \leqq$ $M$ for all $n, k$.

2. Subspaces of $E$ determined by order and type. After the polynomials, the easiest class of entire functions to handle is the class $(\rho, \tau)$, and the properties of its members have been investigated (see [1]). In our terminology, this subspace of $E$ is defined below.

Definition 2.1. Given $\rho \in(0, \infty)$ and $\tau \in[0, \infty)$, let $(\rho, \tau)$ be the set of entire sequences having order $<\rho$ or order $\rho$ and type $\leqq \tau$.

Definition 2.2. For $\rho \in(0, \infty)$ and $\tau \in[0, \infty)$, define $G(\rho, \tau)$ to be the set of complex sequences $x$ such that $\lim \sup n\left|x_{n}\right|^{\rho / n} \leqq \tau e \rho$.

$G(\rho, \tau) \subseteq O(\rho)$, and moreover ([1], Theorem 2.2.10) it is true that

$$
(\rho, \tau)=G(\rho, \tau) \cup O^{\prime}(\rho) \text {. }
$$

Definition 2.4. Suppose $\rho \in(0, \infty)$ and $\tau \in[0, \infty)$. Let $\left\{\varepsilon_{\nu}\right\}_{1}^{\infty} \in 0^{+}$ and let $\alpha_{n}^{\nu}=\left[n /\left(\tau e \rho+\varepsilon_{\nu}\right)\right]^{n / \rho}$. Now set $G(\rho, \tau, \nu)=s\left(\alpha^{\nu}\right)$. (We set $\alpha_{0}^{\nu}=1$.)

It follows from this definition that

$$
G(\rho, \tau)=\bigcap G(\rho, \tau, \nu),
$$

and that $\nu>\mu \Rightarrow G(\rho, \tau, \nu) \subseteq G(\rho, \tau, \mu)$.

We will now prove some general results which will allow us to characterize those matrices which map $(\rho, \tau)$ into $(\mu, \sigma)$.

Let $B_{j}=\bigcap_{\nu} s\left(\alpha^{\nu}(j)\right)$ and let $C_{i}=\bigcap_{\nu} s\left(\beta^{\nu}(i)\right)$. Set $B=\bigcup B_{j}$ and $C=\mathrm{U} C_{i}$. We shall assume the following:

$B$ and $C$ are linear spaces,

(2.7) for every $j$ and $i, \nu>\mu$ implies $s\left(\alpha^{\nu}(j)\right) \subseteq s\left(\alpha^{\mu}(j)\right)$ and 


$$
s\left(\beta^{\nu}(i)\right) \subseteq s\left(\beta^{\mu}(i)\right),
$$

(2.8) for every $j$ and $\mu$, there is a $\nu>\mu$ such that $\sum_{n}\left|\alpha_{n}^{\mu}(j) / \alpha_{n}^{\nu}(j)\right|<\infty$,

(2.9) for every $i$ and $\mu$ there is a $\nu>\mu$ such that $\beta_{n}^{\mu}(i) / \beta_{n}^{\nu}(i) \rightarrow 0$ as $n \rightarrow \infty$.

Lemma 2.10. The matrix $A$ maps $B_{j} \rightarrow C_{i}$ if and only if

(2.11) for every sufficiently large $\nu$ there exist $\mu$ and $M$ such that $\left|a_{n k} \beta_{n}^{\nu}(i) / \alpha_{k}^{\mu}(j)\right| \leqq M$ for all $n, k$.

Proof. (1.9), together with the observation that Theorem 1.8 remains true if in (1.9) " $i$ " is replaced by "sufficiently large $i$ ".

LEMma 2.12. Suppose that for every $i$ and sufficiently large $\nu$ it is true that $\beta_{n}^{\nu}\left(i_{0}\right)=\mathscr{O}\left(\beta_{n}^{\nu}(i)\right)$ as $n \rightarrow \infty$. Then $A$ maps $B \rightarrow C$ if and only if $A$ maps $B \rightarrow C_{i_{0}}$.

Proof. Suppose $A$ maps $B \rightarrow C$. Then ([9], Satz, (4)) for each $j$ there is an $i$ such that (2.11) holds. Our hypothesis then implies that (2.11) holds with $i_{0}$ in place of $i$, whence Lemma 2.10 asserts that $A$ maps each $B_{j}$ into $C_{\imath_{0}}$.

Lemma 2.13. Suppose that for every $j$ and $\mu$ there is a $\gamma$ such that $\alpha_{k}^{\mu}\left(j_{0}\right)=\mathscr{O}\left(\alpha_{k}^{\gamma}(j)\right)$ as $k \rightarrow \infty$. Then $A$ maps $B \rightarrow C$ if and only if $A$ maps $B_{j_{0}} \rightarrow C$.

Proof. Suppose $A$ maps $B_{j_{0}} \rightarrow C$. Then ([9], Satz, (4)) there is an $i$ such that $A$ maps $B_{j_{0}} \rightarrow C_{\imath}$. But then (2.11) is true with $j_{0}$ in place of $j$. Our hypothesis implies that if $j$ is given there exists $\gamma$ such that (2.11) holds with $\gamma$ and $j$ in place of $\mu$ and $j_{0}$. Hence, each $B_{j}$ is mapped into $C_{\imath}$.

THEOREM 2.14. Suppose for each $i$ and sufficiently large $\nu$, $\beta_{n}^{\circ}\left(i_{0}\right)=\mathcal{O}\left(\beta_{n}^{\nu}(i)\right)$ as $n \rightarrow \infty$, and moreover that for every $j$ and $\mu$ there is a $\gamma$ such that $\alpha_{k}^{\prime \prime}\left(j_{0}\right)=\mathcal{O}\left(\alpha_{k}^{\gamma}(j)\right)$ as $k \rightarrow \infty$. Then $A$ maps $B \rightarrow C$ if and only if $A$ maps $B_{j_{0}} \rightarrow C_{i_{0}}$.

Proof. Lemmas 2.12 and 2.13.

CoRollary 2.15. Under the hypotheses of Theorem 2.14, A maps $B \rightarrow C$ if and only if

(2.16) for every sufficiently large $\nu$ there exist $\mu$ and $M$ such that $\left|a_{n k} \beta_{n}^{\prime}\left(i_{0}\right) / \alpha_{k}^{\prime \prime}\left(j_{0}\right)\right| \leqq M$ for all $n, k$. 
Proof. Lemma 2.10.

Let us specialize the situation. Suppose $\left\{\rho_{j}\right\} \in \rho^{-},\left\{\gamma_{\nu}(j)\right\}_{\nu} \in \rho_{j}^{+}$, $\left\{\varepsilon_{\nu}\right\} \in 0^{+}, \quad \alpha_{n}^{\nu}(0)=\left[n /\left(\tau e \rho+\varepsilon_{\nu}\right)\right]^{n / \rho}$, and $\alpha_{n}^{\nu}(j)=n^{n / \tau_{\nu}(j)}$ for $j>0$. Set $B_{0}=G(\rho, \tau)=\bigcap s\left(\alpha^{\nu}(0)\right)$ and $B_{j}=O\left(\rho_{j}\right)=\bigcap s\left(\alpha^{\nu}(j)\right)$ for $j>0$. Then $(\rho, \tau)=B=\bigcup_{0}^{\infty} B_{j}$. Similarly, let $\left\{\mu_{i}\right\} \in \mu^{-}, \quad\left\{\xi_{\nu}(i)\right\} \in \mu_{i}^{+}, \quad \beta_{n}^{\nu}(0)=$ $\left[n /\left(\sigma e \mu+\varepsilon_{\nu}\right)\right]^{n / \mu}$, and $\beta_{n}^{\nu}(i)=n^{n / \xi_{\nu}(i)}$ for $i>0$. Then if $C_{0}=G(\mu, \sigma)=$ $\bigcap s\left(\beta^{\nu}(0)\right)$ and $C_{i}=O\left(\mu_{i}\right)=\bigcap s\left(\beta^{\nu}(i)\right)$ for $i>0$, it follows that $(\mu, \sigma)=$ $C=\mathrm{U}_{0}^{\infty} C_{i}$. Inasmuch as (2.6)-(2.9) and the hypotheses of Theorem 2.14 , with $i_{0}=0=j_{0}$, are met, we have

THEOREM 2.17. The matrix $A$ maps $(\rho, \tau) \rightarrow(\mu, \sigma)$ if and only if $A$ maps $G(\rho, \tau) \rightarrow G(\mu, \sigma)$.

THEOREM 2.18. The matrix $A$ maps $(\rho, \tau) \rightarrow(\mu, \sigma)$ if and only if (2.19) for every sufficiently large $\nu$ there exist $\omega$ and $M$ such that $\left|a_{n k}\right|\left[n /\left(\sigma e \mu+\varepsilon_{\nu}\right)\right]^{n / \mu}\left[\left(\tau e \rho+\varepsilon_{\omega}\right) / k\right]^{k / \rho} \leqq M$ for all $n, k$,

where $\left\{\varepsilon_{\nu}\right\} \in 0^{+}$.

Proof. Corollary 2.15.

Theorem 2.20. The matrix $A$ maps $(\rho, \tau) \rightarrow(\mu, \sigma)$ if and only if (2.21) for each $\beta \in\left(0,(\mu \sigma)^{-1}\right)$ there exist $\alpha \in\left(0,(\rho \tau)^{-1}\right)$ and $M$ such that $\left|\alpha_{n k}\right|(n !)^{1 / \mu}(k !)^{-1 / \rho} \beta^{n / \mu} \alpha^{-k / \rho} \leqq M$ for all $n, k$.

Proof. Suppose (2.19) holds and let $\beta=(\mu \sigma+\delta)^{-1}$ be given. Choose $\nu$ so large that $\varepsilon_{\nu}<\delta e$ and let $\omega$ and $M$ correspond to $\nu$ as in (2.19). Choose $\eta$ so that $0<\eta<\varepsilon_{\omega} e^{-1}$ and let $\alpha=(\rho \tau+\eta)^{-1}$. Then routine calculation, using Stirling's formula, shows that (2.21) is true. Conversely, suppose (2.21) is true, and let $\nu$ be given. Let $\beta=\left(\sigma \mu+\varepsilon_{\nu} e^{-1}\right)^{-1}$ and let $\alpha$ and $M$ correspond to $\beta$ as in (2.21). Choose $\omega$ so that if $\alpha=(\rho \tau+\delta)^{-1}$, then $2 \varepsilon_{\omega}<\delta e$. Then (2.19) holds.

3. An example. We give an example of a matrix $A$ which satisfies (2.21) with $\rho=\mu=1$. Let $\sigma, \tau \in(0, \infty)$. Suppose $f$ is analytic at the origin, and moreover on the closed disc of radius $R>$ $\sigma^{-1}$. Suppose further that $f(0)=0$ and that $|f(z)| \leqq M \leqq R \sigma \tau^{-1}$ on the disc. Let $C=\left(c_{n k}\right)$ be the Sonnenschein matrix generated by $f$ (if $f^{n}(z)=\sum_{k} c_{n k} z^{k}$ for $n \geqq 0$, with $f^{0}(z) \equiv 1$, then $C=\left(c_{n k}\right)$ ). Cauchy's estimate gives $\left|c_{n k}\right| \leqq M^{n} R^{-k}$, so, inasmuch as our restrictions insure that for each $\beta \in(0, \tau)$ there is an $\alpha \in(0, \sigma)$ such that $\alpha R \geqq 1$ and $\beta M \leqq \alpha R$, it follows that $\left|c_{n k}\right| \beta^{n} \alpha^{-k} \leqq(\beta M)^{n}(\alpha R)^{-k}=(\beta M / \alpha R)^{n} /(\alpha R)^{k-n} \leqq$ 
1 (because $f(0)=0$ makes $C$ upper triangular, whence we may assume $k \geqq n)$. Now set $a_{n k}=(k ! / n !) c_{n k}$. Then $A=\left(a_{n k}\right)$ maps $\left(1, \sigma^{-1}\right)$ into $\left(1, \tau^{-1}\right)$.

4. The spaces $E$ and $\mathscr{A}$. Suppose $\mathscr{A}$ is the space of analytic sequences. In [2] and [3], those matrices which map $E \rightarrow E$ are characterized, while in [5] and [6] those which map $\mathscr{A} \rightarrow \mathscr{A}$ are determined. We state these results.

Theorem 4.1. The matrix $A$ maps $E \rightarrow E$ if and only if

(4.2) for every $\beta \in(0, \infty)$ there exist $\alpha \in(0, \infty)$ and $M$ such that $\left|a_{n k}\right| \beta^{n} \alpha^{-k} \leqq M$ for all $n, k$.

THEOREM 4.3. The matrix $A$ maps $\mathscr{A} \rightarrow$ if and only if

(4.4) for every $\alpha \in(0, \infty)$ there exist $\beta \in(0, \infty)$ and $M$ such that $\left|a_{n k}\right| \beta^{n} \alpha^{-k} \leqq M$ for all $n, k$.

The symmetry between (4.2) and (4.4) is unmistakable, and allows an especially easy direct proof of

THEOREM 4.5. The matrix $A$ maps $\mathscr{A} \rightarrow \mathscr{A}$ if and only if the transposed matrix $A^{T}$ maps $E \rightarrow E$.

Proof. By (4.4), $A$ maps $\mathscr{A} \rightarrow \mathscr{A}$ if and only if for each $\alpha>0$ there exist $\beta>0$ and $M$ such that $\left|a_{k n}\right| \beta^{k} \alpha^{-n} \leqq M$ for all $k, n$. Let $\alpha=\gamma^{-1}, \beta=\delta^{-1}$. Then this condition is equivalent to: for each $\gamma>$ 0 there exist $\delta>0$ and $M$ such that $\left|a_{k n}\right| \delta^{-k} \gamma^{n} \leqq M$ for all $n, k$. But this is (4.2) for $A^{T}$.

We note that if Theorem 4.5 is known, then each of Theorems 4.1 and 4.3 follows from the other in the manner of proof of Theorem 4.5. We note further that this theorem allows us to extract from Theorems 7, 8, and 9 of [4] information about $A$, rather than just about $A^{T}$.

\section{REFERENCES}

1. R. P. Boas, Entire Functions, Academic Press, New York, 1954.

2. H. I. Brown, Entire methods of summation, Compositio Math., 21 (1969), 35-42.

3. G. Fricke and R. E. Powell, A theorem on entire methods of summation, Compositio Math., 22 (1970), 253-259.

4. - Functions of bounded index and summability methods, to appear.

5. I. Heller, Contributions to the theory of divergent series, Pacific J. Math., 2 (1952), 153-177.

6. L. A. Raphael, On a characterization of infinite complex matrices mapping the space of analytic sequences into itself, Pacific J. Math., 27 (1968), 123-126. 
7. A. Wilansky, Functional Analysis, Blaisdell, New York, 1964.

8. K. Zeller, Allgemeine Eigenschaften von Limitierungsverfahren, Math. Z., 53 (1951), 463-487.

9. - Transformationen des Durchschnitts und der Vereinigung von Folgenräumen, Math. Nachr., 10 (1953), 175-177.

Received November 30, 1972 and in revised form August 1, 1973.

LEHIGH UNIVERSITY 


\section{PACIFIC JOURNAL OF MATHEMATICS}

\section{EDITORS}

RICHARD ARENS (Managing Editor)

University of California

Los Angeles, California 90024
J. DUGUNDJI*

Department of Mathematics

University of Southern California

Los Angeles, California 90007

D. Gilbarg and J. Milgram

Stanford University

Stanford, California 94305
University of Washington

Seattle, Washington 98105

ASSOCIATE EDITORS
E. F. BECKENBACH
B. H. NeumanN
F. WoLF
K. YosHIDA

\section{SUPPORTING INSTITUTIONS}

\author{
UNIVERSITY OF BRITISH COLUMBIA \\ CALIFORNIA INSTITUTE OF TECHNOLOGY \\ UNIVERSITY OF CALIFORNIA \\ MONTANA STATE UNIVERSITY \\ UNIVERSITY OF NEVADA \\ NEW MEXICO STATE UNIVERSITY \\ OREGON STATE UNIVERSITY \\ UNIVERSITY OF OREGON \\ OSAKA UNIVERSITY
}

\author{
UNIVERSITY OF SOUTHERN CALIFORNIA \\ STANFORD UNIVERSITY \\ UNIVERSITY OF TOKYO \\ UNIVERSITY OF UTAH \\ WASHINGTON STATE UNIVERSITY \\ UNIVERSITY OF WASHINGTON
* * * *
AMERICAN MATHEMATICAL SOCIETY \\ NAVAL WEAPONS CENTER
}

The Supporting Institutions listed above contribute to the cost of publication of this Journal, but they are not owners or publishers and have no responsibility for its content or policies.

Mathematical papers intended for publication in the Pacific Journal of Mathematics should be in typed form or offset-reproduced, (not dittoed), double spaced with large margins. Underline Greek letters in red, German in green, and script in blue. The first paragraph or two must be capable of being used separately as a synopsis of the entire paper. Items of the bibliography should not be cited there unless absolutely necessary, in which case they must be identified by author and Journal, rather than by item number. Manuscripts, in duplicate if possible, may be sent to any one of the four editors. Please classify according to the scheme of Math. Rev. Index to Vol. 39. All other communications to the editors should be addressed to the managing editor, or Elaine Barth, University of California, Los Angeles, California, 90024.

100 reprints are provided free for each article, only if page charges have been substantially paid. Additional copies may be obtained at cost in multiples of 50 .

The Pacific of Journal Mathematics is issued monthly as of January 1966. Regular subscription rate: $\$ 72.00$ a year (6 Vols., 12 issues). Special rate: $\$ 36.00$ a year to individual members of supporting institutions.

Subscriptions, orders for back numbers, and changes of address should be sent to Pacific Journal of Mathematics, 103 Highland Boulevard, Berkeley, California, 94708.

PUBLISHED BY PACIFIC JOURNAL OF MATHEMATICS, A NON-PROFIT CORPORATION

Printed at Kokusai Bunken Insatsusha (International Academic Printing Co., Ltd.), 270, 3-chome Totsuka-cho, Shinjuku-ku, Tokyo 160, Japan.

* C. R. DePrima California Institute of Technology, Pasadena, CA 91109, will replace J. Dugundji until August 1974.

Copyright (C) 1973 by Pacific Journal of Mathematics

Manufactured and first issued in Japan 


\section{Pacific Journal of Mathematics}

\section{Vol. 51, No. $2 \quad$ December, 1974}

Robert F. V. Anderson, Laplace transform methods in multivariate spectral theory .................................................. 339

William George Bade, Two properties of the Sorgenfrey plane . . . . . . . . . . . . 349

John Robert Baxter and Rafael Van Severen Chacon, Functionals on continuous

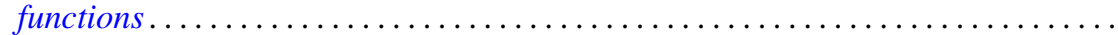

Phillip Wayne Bean, Helly and Radon-type theorems in interval convexity

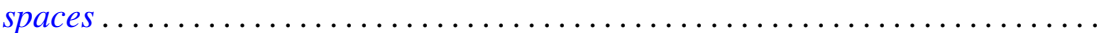

James Robert Boone, On k-quotient mappings $\ldots \ldots \ldots \ldots \ldots \ldots \ldots \ldots \ldots$

Ronald P. Brown, Extended prime spots and quadratic forms . . . . . . . . . . . .

William Hugh Cornish, Crawley's completion of a conditionally upper continuous lattice .............................................

Robert S. Cunningham, On finite left localizations ...................

Robert Jay Daverman, Approximating polyhedra in codimension one spheres

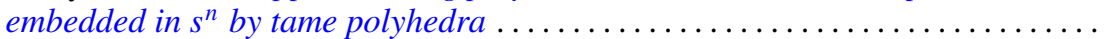

Burton I. Fein, Minimal splitting fields for group representations . . . . . . . . . . . .

Peter Fletcher and Robert Allen McCoy, Conditions under which a connected

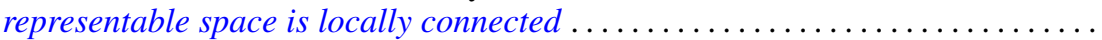

Jonathan Samuel Golan, Topologies on the torsion-theoretic spectrum of a noncommutative ring...

Manfred Gordon and Edward Martin Wilkinson, Determinants of Petrie matrices.

Alfred Peter Hallstrom, A counterexample to a conjecture on an integral condition for determining peak points (counterexample concerning peak points)........

E. R. Heal and Michael Windham, Finitely generated $F$-algebras with applications to Stein manifolds.

Denton Elwood Hewgill, On the eigenvalues of a second order elliptic operator in an unbounded domain ............................

Charles Royal Johnson, The Hadamard product of $A$ and $A^{*}$.

Darrell Conley Kent and Gary Douglas Richardson, Regular completions of Cauchy spaces.

Alan Greenwell Law and Ann L. McKerracher, Sharpened polynomial approximation

Bruce Stephen Lund, Subalgebras of finite codimension in the algebra of analytic functions on a Riemann surface. .

Robert Wilmer Miller, TTF classes and quasi-generators . .

Roberta Mura and Akbar H. Rhemtulla, Solvable groups in which every maximal partial order is isolated ....

Isaac Namioka, Separate continuity and joint continuity...

Alan Saleski, Entropy of self-homeomorphisms of statistical pseudo-metric

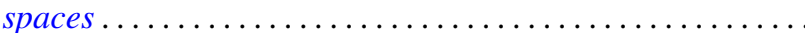

H. A. Seid, Cyclic multiplication operators on $L_{p}$-spaces .....

H. B. Skerry, On matrix maps of entire sequences ............

John Brendan Sullivan, A proof of the finite generation of invariants of a normal

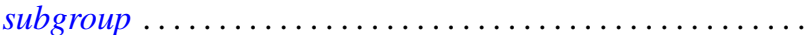

John Griggs Thompson, Nonsolvable finite groups all of whose local subgroups are

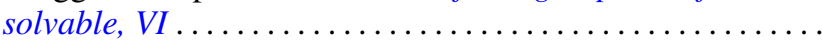

